This item was submitted to Loughborough's Research Repository by the author.

Items in Figshare are protected by copyright, with all rights reserved, unless otherwise indicated.

\title{
Evaluation of the synthetic inertia control using active damping method
}

PLEASE CITE THE PUBLISHED VERSION

https://doi.org/10.1109/ICCEP.2017.8004826

PUBLISHER

(c) IEEE

VERSION

AM (Accepted Manuscript)

LICENCE

CC BY-NC-ND 4.0

REPOSITORY RECORD

Chamorro, Harold R., Naveed R. Malik, Francisco M. Gonzalez-Longatt, and Vijay K. Sood. 2019. "Evaluation of the Synthetic Inertia Control Using Active Damping Method". figshare. https://hdl.handle.net/2134/25774. 


\title{
Evaluation of the Synthetic Inertia Control using Active Damping Method
}

\author{
Harold R. Chamorro, Student Member, IEEE, Naveed R. \\ Malik, Member, IEEE, and Francisco Gonzalez-Longatt, Senior Member, IEEE,
}

\begin{abstract}
The current and massive deployment of nonsynchronous generation is degrading the inertial response in power systems. The addition of an extra control loop, the socalled synthetic inertia, can contribute in the improvement of the frequency response, through an additional power injection. In this paper, the active damping method is used to enhance both, the closed-loop current control and the synthetic inertia control loop. A full aggregated model of a wind turbine generator (WTG) is integrated in a test system. The results obtained show an increase in the power injected into the grid, thereby improving the frequency response after a frequency disturbance. Moreover, the response of the closed current-control loop and voltage loop are presented, in order to show their interaction with the synthetic inertia control.
\end{abstract}

Index Terms-Synthetic Inertia, Frecuency Response, NonSynchronous Generation Integration, Renewable Integration, Active Damping, Closed Current-Control Loop.

\section{INTRODUCTION}

$\mathbf{T}$ HE worldwide concern about the global warming have resulted in government led initiatives of integrating the renewable energy into the power grid, for the production of clean electricity[1]. However, the large scale integration of renewables confront different challenges such as the provision of an uninterrupted supply and the stability impact on the system [2] .

The continuous growth of renewable energy connections into the grid has been possible due to different power electronics interfaces and their control. Voltage Source Converters (VSC) are a mature technology, which is used in Flexible AC Transmission System (FACTS) and High Voltage DC (HVDC) applications [3]. This technology has enabled the interconnection to systems operating at different frequencies and voltages.

One of the aspects that needs consideration is the requirement of maintaining the frequency stability boundaries in the system [4]. The control of the frequency within the nominal limits and adequate response is important in order to avoid undesireable events like outages or blackouts [5].

In order to maintain these limits, the frequency control should act in a manner such that the balance between generation and load always is met. The frequency response in power systems can be divided into different time frames. Initially,

Harold R. Chamorro is a PhD student at KTH Royal Institute of Technology, Stockholm, Sweden, e-mail: hr.chamo@ieee.org, hrcv@kth.se.

Naveed R. Malik is a PhD in Electrical Engineering from KTH Rotyal Institute of Technology, Stockholm, Sweden, e-mail: nurmalik@kth.se.

Francisco Gonzalez-Longatt is with ,, UK, e-mail: fgonzalez an inherent action named as inertial frequency response is present, which takes energy from the rotating masses to oppose a frequency deviation from the scheduled frequency.

In the next stage the automatic governing systems are activated to keep the frequency deviation to an acceptable level (primary control), afterwards, secondary control action is performed which restores the used reserves and the system frequency to its nominal value.

The frequency response degradation under large penetration of non-synchronous generation have been emphasized by several energy associations and Transmission System Operators (TSO) [6], [7]. Therefore, the synthetic inertia control has been formulated and developed by different authors.

The synthetic inertia control can be classified in two categories [8]. Firstly, the inertia emulated by extracting extra power from the Wind Turbine Generator (WTG) rotor, and secondly by deloading the wind turbine to provide headroom for the frequency regulation.

By applying a slight change in the inverter electrical power set-point the kinetic energy in the rotor is released [9].This control action reduces the frequency dip and the rate of change of frequency (ROCOF) [10], [11]. Nevertheless, this extra power can only be extracted for up-to 10s [12].

The second method is by deloading the WT by means of pitching the rotor blades. It is not currently practiced due to the potential loss of revenue [13],[14]. However, if the WTG participates in frequency regulation as a system service, the loss in energy revenue can be compensated [15].

Authors in [16] explains different activation schemes of synthetic inertia for Full Rated Converters (FRC) in order to improve the frequency response in a test power system.

In [17], the synthetic inertia control is added to both the WTG and multi-terminal HVDC transmission system. The proposed analysis shows the coordination between the inertias' extracted from both systems.

Additionally, reference [18] presents the effect of wind integration on the system frequency response on the tie-line interchanges in an interconnected system.

Most of the WT's are equipped with a power electronic converter in order to inject the power into the grid. The control of the grid connected converters relies on the current control. The enhancement of the current-control can improve the power injected to the grid. The frequency response is improved with the addition of the synthetic inertia control loop. A well proven method to improve the current-control response performance is through active damping [19].

The objective of the active damping method is to improve 
the time response characteristics of a system (damping ratio, overshoot, rise time or settling time) by adding an additional feedback loop. The active damping method has been used for several control application purposes, mainly in the field of AC/DC, DC/DC power converters and motor drives [20]. Recently, the active damping method, has been also applied to microgrids [21], vehicular power systems [22], and power distribution operation [23].

The contribution of this paper is based on the application of the active damping method to enhance the closed currentcontrol loop and synthetic inertia control loop in order to improve the power injection, and the frequency response of power systems under penetration of non-synchronous generation.

The paper is organized as follows: In Section II the theoretical preliminaries of current control and the active damping method is presented. In section III, the inertial response is presented and the definition of non-synchronous generation and its relation with the synthetic inertia are introduced. Section IV presents the test system and model of the aggregated WTG. Section $\mathrm{V}$ presents the simulation results considering the two control scenarios; the first one combines the current control based on active damping method together with the basic synthetic inertia control loop, whereas the second scenario, adjust the synthetic inertia loop and remains the current control developed using the active damping method. Finally, the conclusions and future work are given.

\section{Current Control and Active Damping}

A basic structure of VSC-HVDC system is visualized in Figure 1. In the figure 1 it is shown the connection of an AC Source to a grid via back-to-back VSC. Conventional back-to-back VSC system involves two VSC converters with identical configurations, connected via a DC link. In this study, the right-hand side converter, $V S C_{1}$ is controlling the active power injected to the grid and subjected to the extra power injection by the synthetic inertia supplementary control.

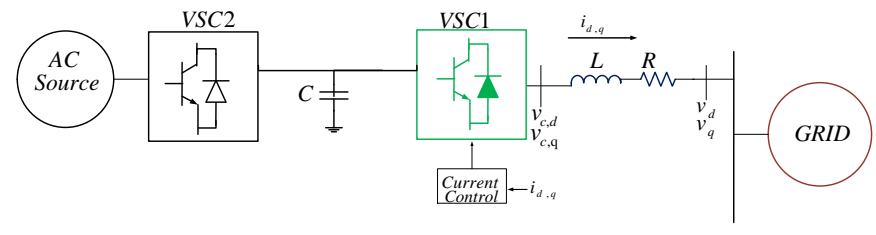

Figure 1. Full Rated Converter

The conventional $d q$ current control has been widely studied in the literature [24],[25]. A synchronous $d-q$ reference approach is convenientionally employed to facilitate VSC control. In this paper the whole system is modeled in the $d-q$ frame, the Phase-Locked Loop (PLL) block is neglected. The dynamics of the $d-q$ axes are:

$$
\begin{aligned}
& R i_{d}+L \frac{d i_{d}}{d t}=v_{c, d}+\omega L i_{q}-v_{d} \\
& R i_{q}+L \frac{d i_{q}}{d t}=v_{c, q}-\omega L i_{d}-v_{q}
\end{aligned}
$$

The inverter decoupled voltage control of $i_{d}$ and $i_{q}$ is noted as follows:

$$
\begin{aligned}
& v_{c, d}=u_{c, d}-L \omega i_{q}+v_{d} \\
& v_{c, q}=u_{c, q}+L \omega i_{d}+v_{q}
\end{aligned}
$$

where, $u_{c, d}$ and $u_{c, q}$ are control signals of the $d$ and $q$ axes respectively.

The active power controller produces the $d$-axis current reference for the inner current controller according to the active power reference. In a similar way, the reactive power controller calculates the $q$-axis currrent reference from the voltage reference. The direct and quadrature axes are coupled via coupling terms $\omega L i_{d}$ and $\omega L i_{q} . R$ and $L$ stands for the equivalent combined resistance and inductance of the phase reactor and transformer.

Figure 3 shows the block diagram of the conventional $d-q$ control approach.

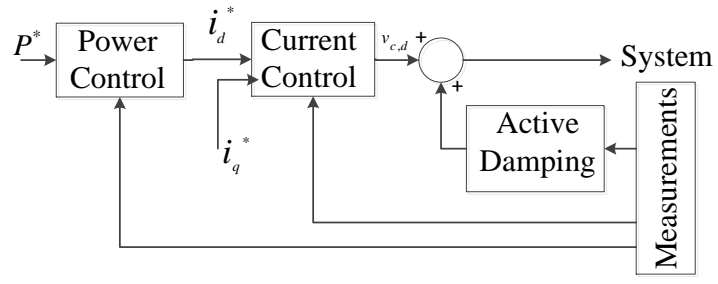

Figure 2. Cascaded Control Structure

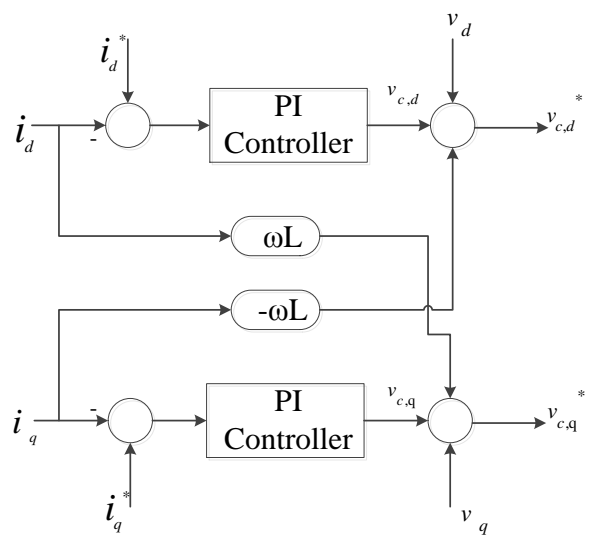

Figure 3. Structural Diagram of the Conventional $d q$ controller

Note that the pulsewidth modulation (PWM) effect has been neglected in the converter.

The cascade control structure of the inverter is shown in Figure 2. Active and reactive power converter currents are controlled in the synchronous reference frame with standards PI controllers. From equations 1 and 2, the plant for the current control is given by:

$$
G(s)=\frac{I_{d}(s)}{V_{d}^{\prime}(s)}=\frac{I_{q}(s)}{V_{q}^{\prime}(s)}=\frac{1}{L s+R}
$$

The active damping loop constant is shown in Figure 4. The active damping loop is equivalent to the classical feedforward form to improve the disturbance rejection capability. The $i_{\text {ref }}$ refers to both $i_{q}$ and $i_{d}$ references. The decoupled system from $v^{\prime}$ to $i$ has the transfer function: 


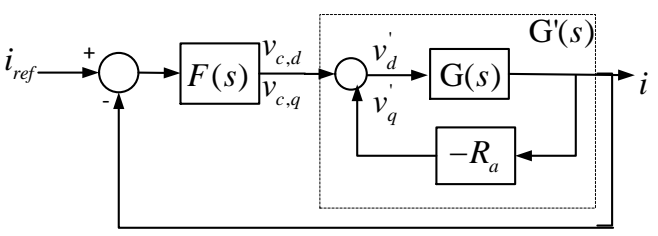

Figure 4. Current Control with the Active Damping Loop

$$
G^{\prime}(s)=\frac{1}{s L+R+R_{a}}
$$

As this is a first-order system, a PI control is appropriate:

$$
F(s)=k_{p}+\frac{k_{i}}{s}
$$

It has been selected $k_{p}=\alpha L$ and $k_{i}=\alpha\left(R+R_{a}\right)$, where $\alpha=\ln (9) / t_{r}$, and $t_{r}$ is the rise time [19].

\section{SynCHRONOUS MACHINE INERTIA}

The swing equation expressed as a first order differential equation is [26]:

$$
\frac{d \omega}{d t}=\frac{1}{2 H}\left(P_{m}-P_{e}\right)
$$

where, $P_{m}$ and $P_{e}$ are the mechanical and electrical power respectively and, $H$ is the inertia constant. The block diagram form representation of the previous equation is shown in the next figure.

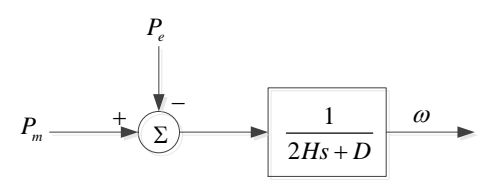

Figure 5. Block Diagram Representation of Swing Equations

In the block diagram, $s$ is the Laplace variable; it replaces $d / d t$ of equations 8 .

The Frequency Containment Response (FCR) is automatically enforced by speed governors, implemented at conventional generator units. This governor relates the generator output power to a reference power and the frequency deviation present in the system. This change in output power is following the governors droop.

\section{A. Non-synchronous Generation and Synthetic Inertia}

Non-synchronous generation in this paper is defined as when the power is supplied or absorbed through power electronic converters (DC-AC) to/from the grid system. Voltage Source Converters (VSC) have been used for wind power turbines namely, Full Rated Converters (FRC), Doubly-Fed Induction Generator (DFIG), and High Voltage Direct Current (HVDC) and Multi-terminal HVDC connection [27].

The non-synchronous generation allows to control active and reactive power control, however the power generation is completely decoupled from the system, and is consequently unable to contribute dynamically to the system [28], [29].
Thus, if the synthetic inertia control option is not added, the decoupling displaces synchronous machines [30].

The synthetic inertial response is an efficient way to contribute to the system inertia. Different control proposals have been used to mimic the inertia; some of them add a derivative term of frequency in the droop control loops equations [31]. The widely used control scheme for the synthetic inertia control is shown in Figure 6. The derivative of the system frequency is obtained and the power reference is modified. To avoid the noise in the measurements, a low-pass filter is used together with the derivative function block.

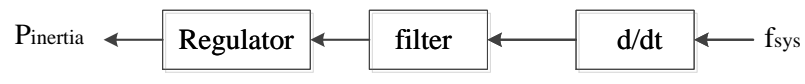

Figure 6. Synthetic Inertia Control Loop

Following the equation 8 , the dynamics of the system frequency $f_{\text {sys }}$ are written as:

$$
2 H_{s y s} \frac{d f_{s y s}}{d t}=\triangle P
$$

The equation above indicates that for a certain power imbalance $\triangle P=P_{m}-P_{e}+P_{n s}$ between the generation and load, $H_{\text {sys }}$ is the aggregated inertia $\sum H$ of a power system and determines the mean change in the rotor speed. A higher aggregate inertia reduces the rate of change in angular speed, leading to an increase in the overall stability of the power system.

The inertial enhancement control from the non-synchronous generation $P_{n s}$ is:

$$
P_{n s}=P_{\text {ord }}-\mathscr{F}_{s i} \frac{d f_{\text {sys }}}{d t}
$$

where, $\mathscr{F}_{s i}$ is the synthetic inertia regulator and $P_{\text {ord }}$ is the ordinary power supplied by the non-synchronous generation. Hence, resulting in the following dynamics of the system frequency:

$$
2\left(H_{s y s}+\frac{\mathscr{F}_{s i}}{2}\right) \frac{d f_{s y s}}{d t}=P_{m}-P_{e}+P_{\text {ord }}
$$

Thus, by integrating the inertial control loop, the overall system inertia can be improved.

\section{System Description AND Modelling}

\section{A. Test System}

The single line diagram of the test case system is shown in Figure 7. The test system consists of two fully symmetrical areas linked together by two $230 \mathrm{kV}$ lines of $220 \mathrm{~km}$ length [32]. Each area is equipped with two identical round rotor generators rated $20 \mathrm{kV} / 900 \mathrm{MVA}$. The nominal power system frequency for the test case model is $50 \mathrm{~Hz}$.

For study purposes, in this paper, one of the generators has been replaced by non-synchronous generation by an aggregated wind farm model. 


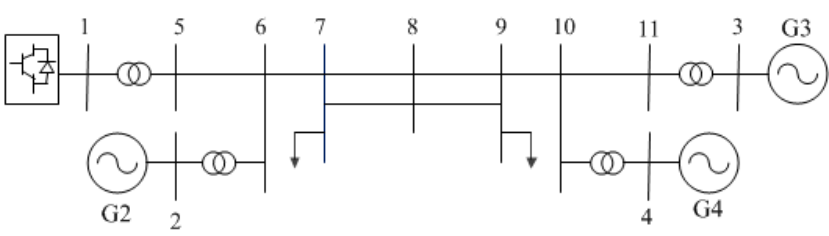

Figure 7. Two Area Test System including non-synchronous generation

\section{B. Wind Farm Aggregated Model}

The following equation is known to be a good representation of the mechanical power that can be extracted from the generator shaft of a wind turbine [33]:

$$
P_{t}=\frac{1}{2} \rho A v^{3} C_{p}(\lambda, \beta)
$$

where, $\rho$ is the air density, $A$ is the area swept by the rotor blades, $v$ is the wind speed, $\beta$ denotes pitch angle, and $C_{p}$ is a function of the pitch angle of the turbine blade. The tip speed ratio $\lambda$ is defined as:

$$
\lambda=\frac{\omega_{t} R}{v}
$$

where, $\omega_{t}$ and $R$ are the shaft speed and rotor radium respectively.

Figure 8 shows a simplified block diagram of the active power control of a WTG model [33]. The inputs of this block are the incoming wind, the electrical power injected by the WTG $P_{g}$, and the power set point $P_{\text {set }}$ which is dominated by the current control injection. Hence, controlling the $d$-axis current is the equivalent of controlling the power output and controlling the $q$-axis current correspond either to voltage or reactive power.

The torque is controlled through a speed controller. The normal approach is to use the rotational speed of the turbine as input signal. This signal provides a reference torque, if the electric torque is larger than the mechanical torque the turbine will decelerate and the electric torque set point will decrease.

The mechanical speed regulation in the power limiting region is implemented by controlling the blade pitch angle $\beta$. The control signal $u_{\beta}$ is given by the following PID control scheme [34]:

$$
\begin{gathered}
u_{\beta}=-C_{p t}(s)\left(\omega_{r e f}-\omega_{m}\right) \\
C_{p t}(s)=K_{p p}\left(1+\frac{1}{T_{i} s}+\frac{T_{d} s}{1+\gamma T_{d} s}\right)
\end{gathered}
$$

where, $\omega_{r e f}$ is the reference for the regulation, and $K_{p p}$, $T_{i}, T_{d}$ and $\gamma$ denote control parameters.

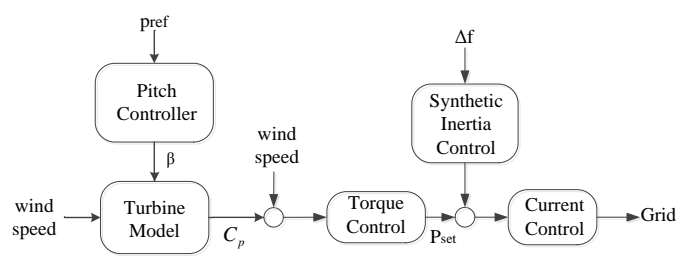

Figure 8. Active Power Wind Farm Schematic Diagram
The main purpose of the synthetic inertia controller $\mathcal{F}_{s i}$ is to improve the instantaneous frequency deviation. The active damping approach is applied to the the current control to improve the power injection response.

\section{Simulation Results}

\section{A. Current Control Based Active Damping and Synthetic Inertia Control}

Initially the current control based on the active damping method plus the synthetic inertia (SI) control is tested. The impact of the proposed controllers, active damping (AD) and SI are analysed through time-domain simulations carried out in Matlab/Simulink.

The frequency response is evaluated during an increase in the load of $600 \mathrm{MW}$ at bus $\mathrm{n}$ at $t=80 \mathrm{~s}$. Figure 9shows the frequency response for three signals where NSI, SI and SI active damping stands for the no additional/supplementary control (in grey), the basic current-control and the synthetic inertia control (in red), and the current control based on the active damping method plus the synthetic inertia control (in blue). Figure 10 shows the power injection from the converter. It also shows the active power signal from a generator $\left(G_{4}\right)$ and the response of the converter, with the basic current control plus the synthetic inertia control and, with active damping current-control. The difference between the basic current control and the one with active damping method.

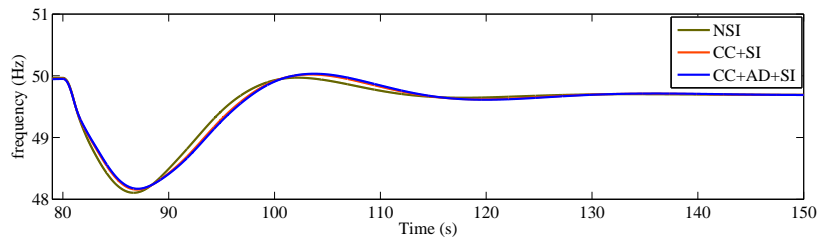

Figure 9. Frequency Response after Load is increased

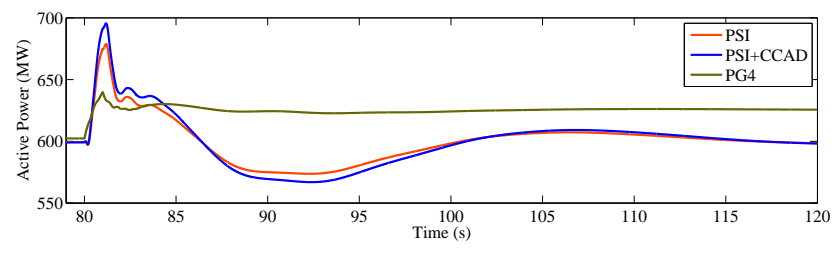

Figure 10. Power Injection of the converter during an increase in the load

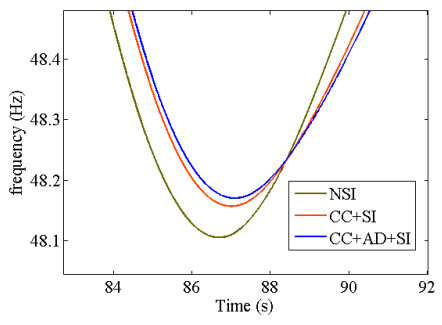

(a) Frequency Nadir

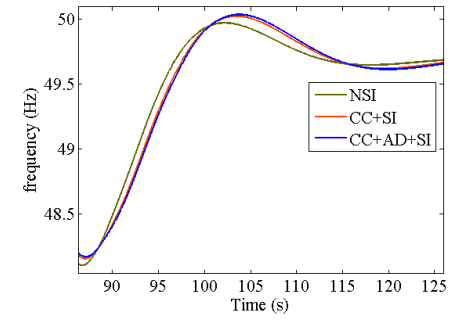

(b) Recovering Time
Figure 11. Frequency Response (Nadir and 
The changes in the frequency are shown in Figure 11. The frequency nadir without the synthetic inertia control loop reaches $f_{\min }=48.11$, whereas with the additional controllers reaches $f_{\min }=48.17$ and $f_{\min }=48.15$ respectively. Figure 11 also shows that the synthetic control action after being activated has recovering time.

Furthermore, two more different aspects are presented. The current and dc link actions. The $d$-axis current action under the same frequency event is shown in Figure 12. The current increases as the frequency drops.

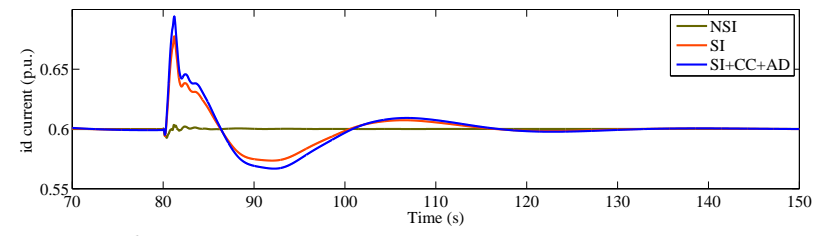

Figure 12. $d$-axis current

The $v d$ signal is shown in Figure 13. As it can be seen, there is a fluctuation due to the frequency drops, however, after five seconds the voltage reaches a desired value. The stable operation of the voltage closed-loop control is important for the stable control operation of the power electronic converter, generator, and the whole system. The result shows that desired control response is adequate during the disturbance.

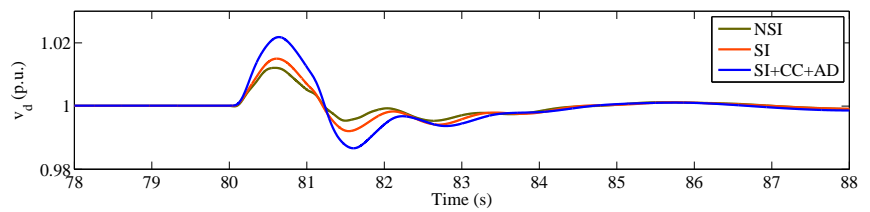

Figure 13. $d$-axis voltage

\section{B. Synthetic Inertia Control Adjustment}

A second control scenario is presented where the synthetic control constants are improve remaining the current-control with the active damping control. The frequency response of the NSI and the SI with the current control and the synthetic inertia control loop is shown in Figure 14. From the figure it can be observed that frequency nadir reduces considerably with the SI-AD-CC.

The frequency nadir with the both controllers based on active damping working reaches $f_{\min }=48.76$ compared to the previous control with of $f_{\min }=48.16$. The restoration time

Figure 15 shows the time response of the dc voltage under the interaction of both the controllers.

\section{Conclusions}

In this paper, current control based on active damping principles and its effect on the synthetic inertia was presented. The active damping method was used to improve the current control loop, in order to improve the the power injection performance. A modified version of the two area test system is used where it is integrated into a fully aggregated wind farm model including the system dynamics.

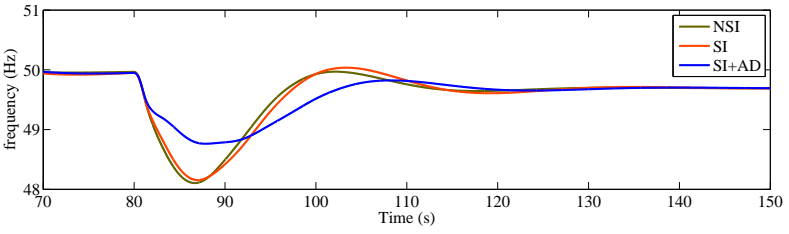

(a) Frequency Response with Active Damping in both Controllers.

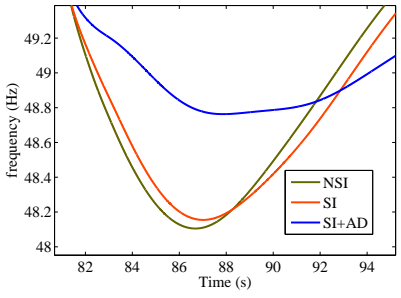

(b) Frequency Nadir

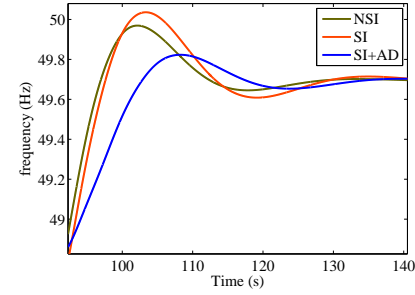

(c) Restoration Time
Figure 14. Frequency Response with Both AD controllers

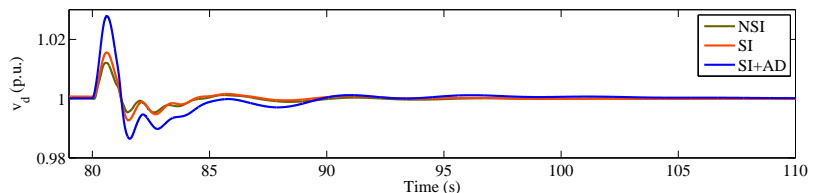

Figure 15. $\quad v d$ time response with Active Damping in both Controllers

It was shown that the frequency response in the test system was significantly improved. Even though the current control with the addition of the active damping improved the frequency response, the improvement is more effective with the variation of the constant in the synthetic control loop.

Since the current control is the core of the VSC it is necessary to assure that it gives an appropriate response for and additional power being injected, as being commanded by the synthetic inertia control during the frequency events.

The robustness of a current-control proves its effectiveness on the power injection. Therefore the system effort is maintained in the correct boundaries.

It was shown that the synthetic inertia control releases the active power (inertial power), effectively diminishing the frequency nadir in the test system, however it has been observed a recovery time for WTG.

It has been observed also how the current and voltage signals are affected by the frequency events and the response of the controllers.

Future work might include the modulation model of the converter in order to evaluate the impact of the control on the modulation side. Also, it can be applied other control methods for the synthetic inertia control loop.

\section{REFERENCES}

[1] E. Bompard, G. Fulli, M. Ardelean, and M. Masera, "It's a Bird, It's a Plane, It's a...Supergrid!: Evolution, Opportunities, and Critical Issues for Pan-European Transmission", IEEE Power and Energy Magazine, vol. 12, no. 2, pp. 40-50, Mar. 2014.

[2] M. Lorenzo, U. Burdalo, R. Veguillas, A. Birke, O. Despouys, I. P. Byriel, C. Druet, A. Abart, G. Bissel, and M. Sebastian-Viana, "The Proof Is in the Putting: Large-Scale Demonstrations of Renewables Integration Showcase RealWorld Solutions", IEEE Power and Energy Magazine, vol. 13, no. 1, pp. 75-83, Jan. 2015. 
[3] W. Litzenberger, K. Mitsch, and M. Bhuiyan, "When It's Time to Upgrade: HVdc and FACTS Renovation in the Western Power System", IEEE Power and Energy Magazine, vol. 14, no. 2, pp. 32-41, Mar. 2016.

[4] N. W. Miller, "Keeping It Together: Transient Stability in a World of Wind and Solar Generation", IEEE Power and Energy Magazine, vol. 13, no. 6, pp. 31-39, Nov. 2015.

[5] P. Kundur, J. Paserba, V. Ajjarapu, G. Andersson, A. Bose, C. Canizares, N. Hatziargyriou, D. Hill, A. Stankovic, C. Taylor, T. V. Cutsem, and V. Vittal, "Definition and classification of power system stability IEEE/CIGRE joint task force on stability terms and definitions", IEEE Transactions on Power Systems, vol. 19, no. 3, pp. 1387-1401, Aug. 2004.

[6] J. Conto, "Grid challenges on high penetration levels of wind power", in 2012 IEEE Power and Energy Society General Meeting, 2012, pp. 1-3.

[7] M. J. Till, Y. Liu, Y. Liu, M. Patel, and T. King, "Frequency response of the Eastern Interconnection due to increased wind generation", in 2014 IEEE PES General Meeting | Conference Exposition, Jul. 2014, pp. 1-5.

[8] F. Wilches-Bernal, J. Chow, and J. Sanchez-Gasca, "A Fundamental Study of Applying Wind Turbines for Power System Frequency Control", IEEE Transactions on Power Systems, vol. PP, no. 99, pp. 1-10, 2015.

[9] L.-R. Chang-Chien and Y.-C. Yin, "Strategies for Operating Wind Power in a Similar Manner of Conventional Power Plant”, IEEE Transactions on Energy Conversion, vol. 24, no. 4, pp. 926-934, Dec. 2009.

[10] J. Mauricio, A. Marano, A. Gomez-Exposito, and J. Martinez Ramos, "Frequency Regulation Contribution Through Variable-Speed Wind Energy Conversion Systems", IEEE Transactions on Power Systems, vol. 24, no. 1, pp. 173-180, Feb. 2009.

[11] N. Ullah, T. Thiringer, and D. Karlsson, "Temporary Primary Frequency Control Support by Variable Speed Wind Turbines - Potential and Applications", IEEE Transactions on Power Systems, vol. 23, no. 2, pp. 601-612, May 2008.

[12] J. Aho, A. Buckspan, J. Laks, P. Fleming, Y. Jeong, F. Dunne, M. Churchfield, L. Pao, and K. Johnson, "A tutorial of wind turbine control for supporting grid frequency through active power control", in American Control Conference (ACC), 2012, 2012, pp. 3120-3131.

[13] S. Wang, J. Hu, X. Yuan, and L. Sun, "On Inertial Dynamics of Virtual-Synchronous-Controlled DFIG-Based Wind Turbines", IEEE Transactions on Energy Conversion, vol. 30, no. 4, pp. 1691-1702, Dec. 2015.

[14] A. Bucurenciu, M. Ndreko, M. Popov, and M. A. M. M. v. d. Meijden, "Frequency response using MTDC grids: A comparative study of common methods", in PowerTech, 2015 IEEE Eindhoven, Jun. 2015, pp. 1-6.

[15] H. Chvez, R. Baldick, and J. Matevosyan, "The Joint Adequacy of AGC and Primary Frequency Response in Single Balancing Authority Systems", IEEE Transactions on Sustainable Energy, vol. 6, no. 3, pp. 959-966, Jul. 2015.

[16] F. Gonzalez-Longatt, "Activation schemes of synthetic inertia controller on full converter wind turbine (type 4)", in 2015 IEEE Power Energy Society General Meeting, Jul. 2015, pp. 15 .

[17] F. Bianchi and J. Dominguez-Garcia, "Coordinated Frequency Control Using MT-HVDC Grids With Wind Power Plants", IEEE Transactions on Sustainable Energy, vol. PP, no. 99, pp. 1-8, 2015.

[18] N. Nguyen and J. Mitra, "An Analysis of the Effects and Dependency of Wind Power Penetration on System Frequency Regulation", IEEE Transactions on Sustainable Energy, vol. 7, no. 1, pp. 354-363, Jan. 2016.

[19] J. Dannehl, F. W. Fuchs, S. Hansen, and P. B. Thogersen, "Investigation of active damping approaches for PI-based current control of grid-connected PWM converters with LCL filters", in 2009 IEEE Energy Conversion Congress and Exposition, Sep. 2009, pp. 2998-3005.

[20] M. Wagner, T. Barth, C. Ditmanson, R. Alvarez, and S. Bernet, "Discrete-time optimal active damping of LCL resonance in grid connected converters by proportional capacitor current feedback", in 2013 IEEE Energy Conversion Congress and Exposition, Sep. 2013, pp. 721-727.

[21] M. Wu and D. D. C. Lu, "An active damping method for stabilization of cascaded connected two stage converter systems with constant power loads in DC microgrids", in 2014 IEEE International Symposium on Circuits and Systems (ISCAS), Jun. 2014, pp. 2664-2667.

[22] X. N. Zhang, D. M. Vilathgamuwa, K. J. Tseng, B. S. Bhangu, and G. Chandana, "A loop cancellation based active damping solution for constant power instability in vehicular power systems", in 2012 IEEE Energy Conversion Congress and Exposition (ECCE), Sep. 2012, pp. 1182-1187.

[23] W. R. Ryckaert, K. D. Gusseme, D. M. V. d. Sype, J. J. Desmet, and J. A. Melkebeek, "Adding damping in power distribution systems by means of power electronic converters", in 2005 European Conference on Power Electronics and Applications, Sep. 2005, 10 pp.-P.10.

[24] M. P. Kazmierkowski and L. Malesani, "Current control techniques for three-phase voltage-source PWM converters: a survey", IEEE Transactions on Industrial Electronics, vol. 45, no. 5, pp. 691-703, Oct. 1998.

[25] B. Bahrani, S. Kenzelmann, and A. Rufer, "MultivariablePI-Based Current Control of Voltage Source Converters With Superior Axis Decoupling Capability", IEEE Transactions on Industrial Electronics, vol. 58, no. 7, pp. 3016-3026, Jul. 2011.

[26] P. Kundur, Power System Stability and Control, McGraw-Hill. New York, 1994.

[27] H. R. Chamorro, C. A. Ordonez, J. C. Peng, and M. Ghandhari, "Non-synchronous generation impact on power systems coherency", Transmission Distribution IET Generation, vol. 10, no. 10, pp. 2443-2453, 2016.

[28] G. Lalor, A. Mullane, and M. O’Malley, "Frequency control and wind turbine technologies", IEEE Transactions on Power Systems, vol. 20, no. 4, pp. 1905 -1913, Nov. 2005.

[29] Y. Wang, G. Delille, H. Bayem, X. Guillaud, and B. Francois, "High wind power penetration in isolated power systems assessment of wind inertial and primary frequency responses", IEEE Transactions on Power Systems, vol. 28, no. 3, pp. 24122420, 2013.

[30] D. Banham-Hall, C. Smith, G. Taylor, and M. Irving, "Investigating the limits to inertial emulation with large-scale wind turbines with direct-drive permanent magnet generators", in UKACC International Conference on Control 2010, Sep. 2010, pp. 1-6.

[31] Z. Miao, L. Fan, D. Osborn, and S. Yuvarajan, "Wind Farms With HVdc Delivery in Inertial Response and Primary Frequency Control", IEEE Transactions on Energy Conversion, vol. 25, no. 4, pp. 1171-1178, Dec. 2010.

[32] M. Klein, G. Rogers, and P. Kundur, "A fundamental study of inter-area oscillations in power systems", IEEE Transactions on Power Systems, vol. 6, no. 3, pp. 914-921, Aug. 1991.

[33] H. Dharmawardena, K. Uhlen, and S. S. Gjerde, "Modelling wind farm with synthetic inertia for power system dynamic studies", in 2016 IEEE International Energy Conference (ENERGYCON), Apr. 2016, pp. 1-6.

[34] N. Horiuchi and T. Kawahito, "Torque and power limitations of variable speed wind turbines using pitch control and generator power control", in Power Engineering Society Summer Meeting, 2001, vol. 1, Jul. 2001, 638-643 vol.1. 